\title{
Research on Seismic Performance of Spatial Beam to Column Connection with T- Stubs
}

\author{
Xin BU \\ School of Civil Engineering and Architecture \\ Wuhan University of Technology, \\ Wuhan, Hubei, China \\ e-mail: carville@163.com
}

\author{
Qian GU \\ School of Civil Engineering and Architecture \\ Wuhan University of Technology, \\ Wuhan, Hubei, China \\ e-mail: guqian218@126.com
}

\author{
Xinwu WANG \\ Department of Civil Engineering \\ Luoyang Institute of Science and Technology \\ Luoyang, Henan, China \\ e-mail: lywxw518@163.com
}

\begin{abstract}
This paper studies the seismic performance of spatial semi-rigid beam-column connections with $T$-stubs. The middle column connection of steel frame as the research objects and there is one spatial $\mathbf{T}$-stub connection specimen and one plane T-stub connection specimen. Spatial quasi-static tests and finite element analysis are carried out, which load is applied to the column. According to the results of quasi-static tests and finite element calculations, difference of joints' rotational stiffness, hysteretic property, ductility coefficient and energy dissipation characteristics are analyzed. It is verified that the mechanical characteristics of spatial semirigid joint under spatial load are different from plane semirigid joint under plane load.
\end{abstract}

Keywords-steel frame; semi-rigid connection; spatial semirigid joint; quasi-static test; seismic performance

\section{INTRODUCTION}

Over the past dozen years, Fractures observed at the beam to column connections in steel moment-resisting frames have led structural engineers to investigate the hysteretic behavior of such connections, especially semirigid connections[1] [6]. However, it is worth noting that various experimental programs were carried out to monotonically and cyclically test connections on specimens. Two limitations are mainly presented in current studies. Firstly, these studies are mainly designed for connections in planar frames, i.e., for frame's columns made from hot-rolled $\mathrm{H}$ sections, only the load applied to the planar joints on the major axis, where the bending stiffness is considerably greater than that on the minor axis, is taken into consideration, while the influences of the load applied to the minor axis, where the bending stiffness is smaller, and of the actual force state of the joints in spatial frame is ignored. Secondly, most of the tests, the beam was loaded with an actuator while the column was kept fixed. The method of application to the beam ends can be realized more easily and basically consistent with the actual forced state of beam to column connection [7] [8]. However, this method does not take into account the P- $\Delta$ second-order effect on the column. Based on the above, in earthquake, the spatial beam to column connections are under loads from more than one direction in spatial frame. These connections are subjected to bending moments, torsional moment, shear forces and axial force passing from the beams to the column in several directions. As a result of the combined effects of these internal forces, the performances and destruction mechanisms of the joints in 3D frame are very complicated [9] [12]. Therefore, studying the mechanical property of spatial connection that is under loads from two directions is important in terms of enhancing the design of steel frame systems and improves the earthquake resistance performance.

\section{DESIGN OF THE TEST SPECIMEN}

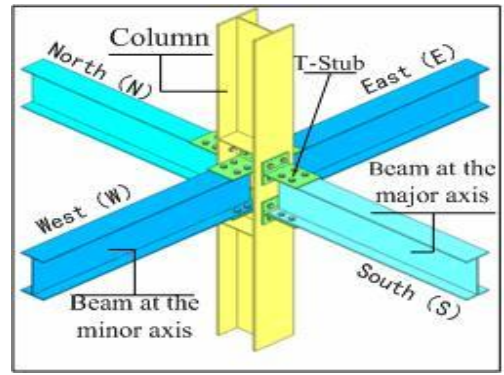

Figure 1. Spatial joint specimen

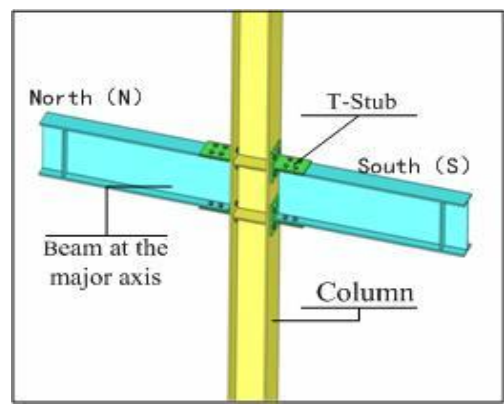

Figure 2. Planar joint specimen 
Beam to column connection with $\mathrm{T}$ stub is one of the typically semi-rigid beam-column connections, and they feature in large rotational stiffness and bearing capacity [13] [14]. As shown in Figure1, pseudo static tests were carried out on the spatial interior joint in spatial frame with $\mathrm{T}$ stub. Meanwhile, to study the different characteristics between the planar joint and the spatial joint, pseudo static tests were also carried out on he planar joint, See Figure2. The models for all the test specimens were made at a scale of $1: 1$. The beams of the spatial joint were connected to the column with $\mathrm{T}$ stubs and high-strength bolts. In the plane of the joint's major axis, the beams were connected to the column flanges. In the plane of the minor axis, the beams were connected to the column web. Columns and beams in the test were made from $\mathrm{WH} 300 \times 300 \times 10 \times 15$ and $\mathrm{NH} 350 \times 175 \times 7 \times 11$ hot rolled $\mathrm{H}$ sections. The T stubs were T270 $\times 200 \times 9 \times 14$. See Table 1 for detailed information about the joints. All the test specimens at the joints were connected with high strength friction bolts (Grade 10.9, M22). The beams and columns were fixed in accordance with the Code for Acceptance of Construction Quality of Steel Structures (GB50205-2001).

TABLE I. PARAMETERS OF THE TEST SPECIMENS

\begin{tabular}{|c|c|c|c|c|c|}
\hline $\begin{array}{c}\text { Joint } \\
\text { ID }\end{array}$ & $\begin{array}{c}\text { Length of } \\
\text { column } \\
(\mathbf{m m})\end{array}$ & $\begin{array}{c}\text { Length of } \\
\text { the beam } \\
\text { at the } \\
\text { major axis } \\
(\mathbf{m m})\end{array}$ & $\begin{array}{c}\text { Length of } \\
\text { the beam } \\
\text { at the } \\
\text { minor axis } \\
(\mathbf{m m})\end{array}$ & $\begin{array}{c}\text { Bolt } \\
\text { Spec. }\end{array}$ & $\begin{array}{c}\text { Bolt } \\
\text { Qty. }\end{array}$ \\
\hline PJD & 3000 & 1800 & - & M22 & 16 \\
\hline KJD & 3000 & 1800 & 1900 & M22 & 56 \\
\hline
\end{tabular}

All beams, columns, and T stubs were made from Q235B steel from the same lot. The steel has been made into test specimens according to Metallic Material Room Temperature Tension Test Methods (GB/T288.1-2010) for the strain-stress curve uniaxial tension tests. See Table 2 for the outcome of the steel's mechanical performance tests.

TABLE II. MECHANICAL PERFORMANCES OF THE STEEL USED FOR THE TEST

\begin{tabular}{|c|c|c|c|c|}
\hline \multirow{2}{*}{ Steel category } & \multicolumn{4}{|c|}{ Test item } \\
\cline { 2 - 5 } & $\boldsymbol{f}_{\boldsymbol{y}}(\boldsymbol{M P a})$ & $\boldsymbol{f}_{\boldsymbol{u}}(\boldsymbol{M P a})$ & $\boldsymbol{A}(\boldsymbol{\%})$ & $\boldsymbol{E}(\boldsymbol{G P a})$ \\
\hline $\begin{array}{c}\text { Columns' web and flange } \\
\text { average value of tensile } \\
\text { strength }\end{array}$ & 271 & 457 & 36 & 209 \\
\hline $\begin{array}{c}\text { Beams' web and flange } \\
\text { average value of tensile } \\
\text { strength }\end{array}$ & 270 & 460 & 28.5 & 209 \\
\hline $\begin{array}{c}\text { T stubs' web and flange } \\
\text { average value of tensile } \\
\text { strength }\end{array}$ & 260 & 456 & 36.5 & 207 \\
\hline
\end{tabular}

III. TEST DEVICES

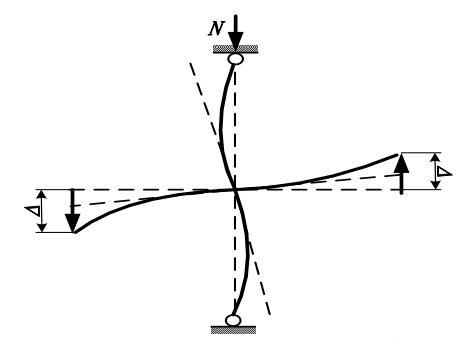

(a) Load is applied to the beam end of the joint

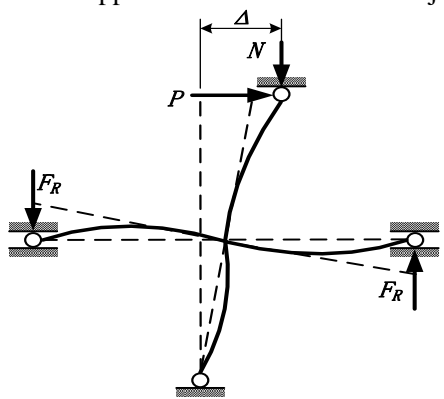

(b) Load is applied to the column end of the joint

Figure 3. Mechanical models at the beam to column joint for the pseudo static tests

At present, pseudo static tests for joints are mainly carried out in two ways: loads applied to beam ends and loads applied to column ends, as shown in Figure 3 (a) and (b). The method of application to the beam ends can be realized more easily. However, this method does not take into account the P- $\Delta$ second-order effect on the column. Therefore, the method of application at column ends was adopted in this study. On the basis of the mechanical characteristics of beam to column connection in spatial frame, two pairs of horizontal actuators were separately placed in the joints' major axis plane and minor axis plane. The two planes were orthogonal to each other. Each pair of actuators was fixed on an L-shaped reaction wall, and horizontal loads were applied to both ends of the column. A vertical actuator fixed with a reaction frame was arranged at the top of the column so that axial pressure can be applied on column. The vertical actuator can horizontally move with the end in both directions. The above five actuators were controlled by an electro hydraulic servo testing system. The north-south direction was the joint's major axis plane, and the east-west direction was the minor axis plane. At the foot of the column, a hinged support that was able to move in all directions was used to achieve slide displacement due to orthogonal loads in two directions. Hinged supports that were able to follow the movement of the beam ends were arranged at the beam ends in the east (E), west (W), north $(\mathrm{N})$, and south $(\mathrm{S})$ directions. The supports were hinged in the plane of the applied loads and moved with the ends out of the planes of loads. Meanwhile, pressure sensors were placed at the upper and lower ends of each beam to measure the reaction force of the supports at the beam ends. Each of the beam-end supports was placed on a lattice truss that has 
large stiffness, take the spatial joint specimen experiment as an example, as shown in Figure 4 and test load step curve is shown in Figure 5 [15], the test sites are shown in Figure 6.

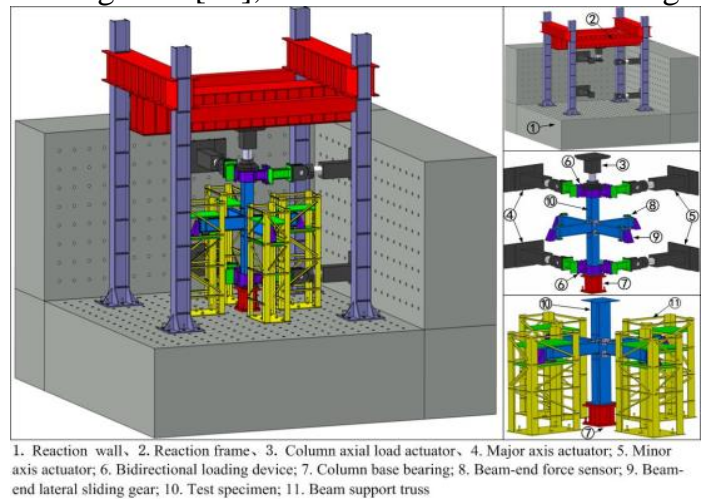

Figure 4. Pseudo-static test system of the spatial joint

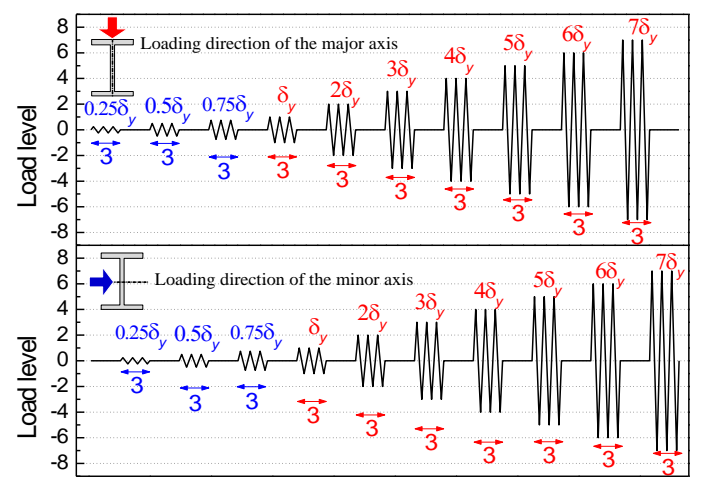

Figure 5. Bidirectional load step curve

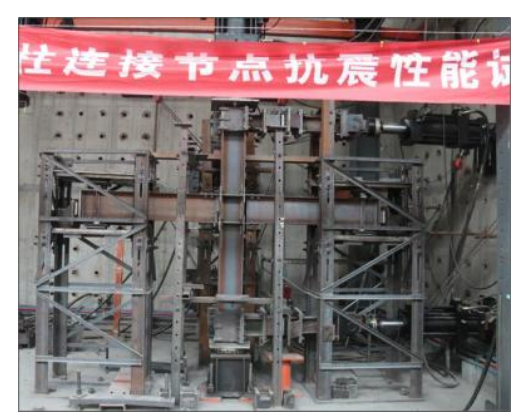

(a) Planar joint test site

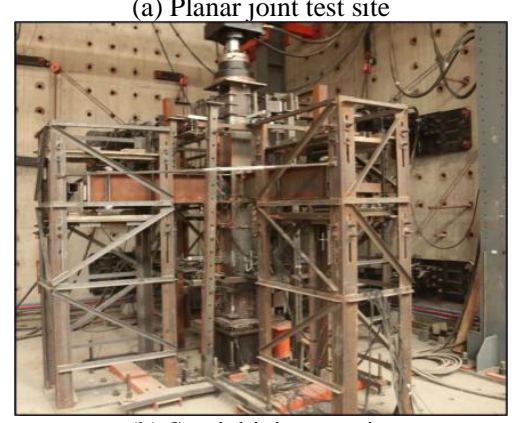

(b) Spatial joint test site

Figure 6. Spatial joints test site

\section{FINITE ELEMENT MODEL}

In order to analyze and understand the behaviors of beam-to-column joints under cyclic load, the Finite Element Method software ABAQUS was used. A three-dimensional (3-D) finite element model of the spatial interior joint and planar joint was developed on standard static analysis. Figure 7 shows the meshing established for planar joint model and spatial joint model was shown in Figure 8. In order to obtain some simplification on the modeling, only fine mesh was defined when closer to the contact part of the model. 8-node linear brick elements with reduced integration C3D8R were considered for most components. A series of contact interactions were defined between the connector and the column/beam, and between the bolts and the connected members. Surface-to-surface contacts with finite sliding were employed for all the contacting pairs, where "Hard" contact was assumed for the normal contacting behavior and a friction coefficient of 0.4 was assumed for the tangential behavior, as recommended by the Chinese Standard. It is also noted that the diameter of the bolt shank was taken as the same as the bolt hole (i.e. no bolt hole clearance) to enable initial contact and thus to allow good numerical convergence. Before the cyclic loading, the $190 \mathrm{kN}$ pretightening force was applied to each bolt.

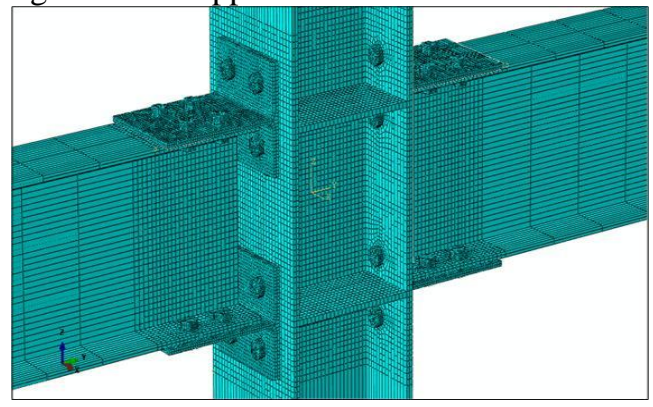

Figure.7 Finite element model of planar joint

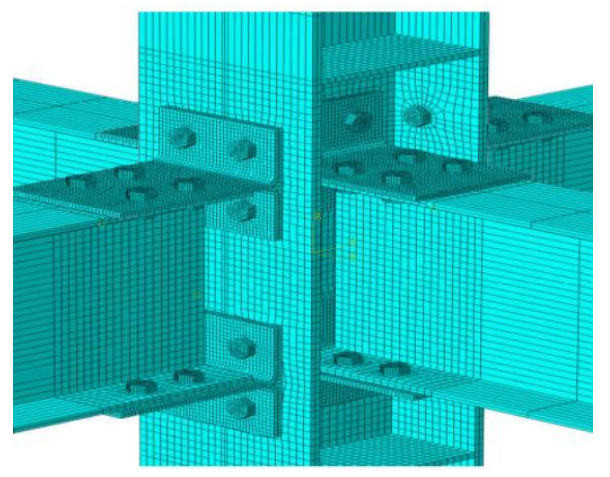

Figure 8. Finite element model of spatial joint

\section{TEST RESUltS AND FINITE ELEMENT ANALYSIS}

\section{A. Yielding Behaviors and Failure Modes}

According to compare experimental and numerical results, whether planar joint or spatial joint the yielding locations tended to be concentrated on the T-stubs. For the test specimen at the planar joint (PJD) under the cyclic load, 
the $\mathrm{T}$ stubs on both sides of the column at the planar joint (PJD) not only became quite plastic and deformed but also transmitted the internal forces into the center of the joint so that the column's web panel caused shear deformation (Figure 9). The spatial joint (KJD) in 3D frame have the feature of destruction in the plane of the minor axis occurred at the junction of column's web and flange. The main reason was that two beams are connected to the column's web in the direction of the minor axis. The flanges of the T stubs were thicker than the column's web, and therefore, when the plane of the minor axis was under load, the T stubs on both sides of the column's web caused the column's web to deform in the opposite direction outside of the plane due to the pull and press effects. Destruction of cracks showed in Figure 10.

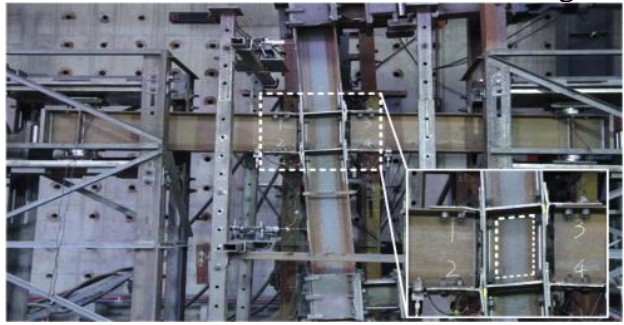

(a) Fracture failures of planar joint

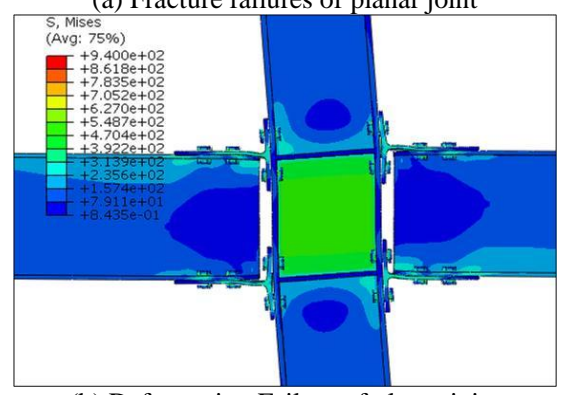

(b) Deformation Failure of planar joint

Figure 9. Fracture failures of planar joint

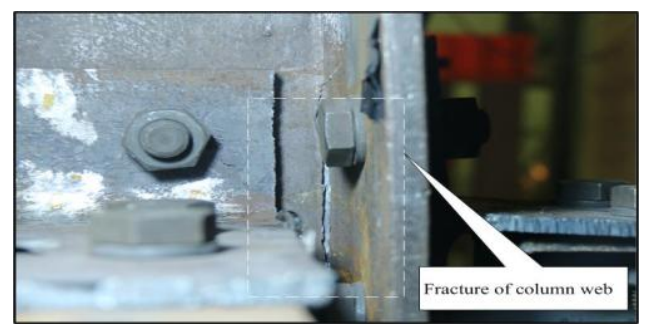

(a) Fracture failures of spatial joint

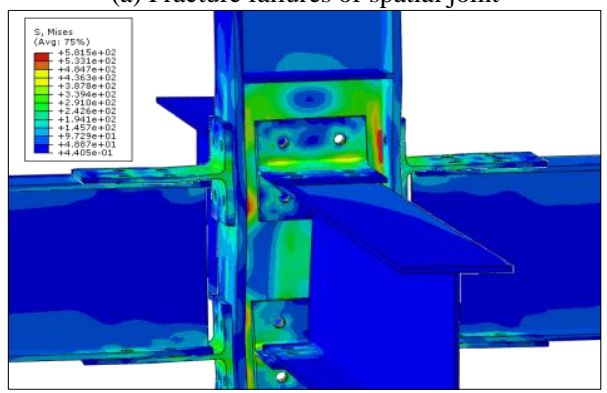

(b) Deformation failure of spatial joint

Figure 10. Fracture failures of spatial joint

\section{B. Hysteresis Curve and Skeleton Curve Analysis}
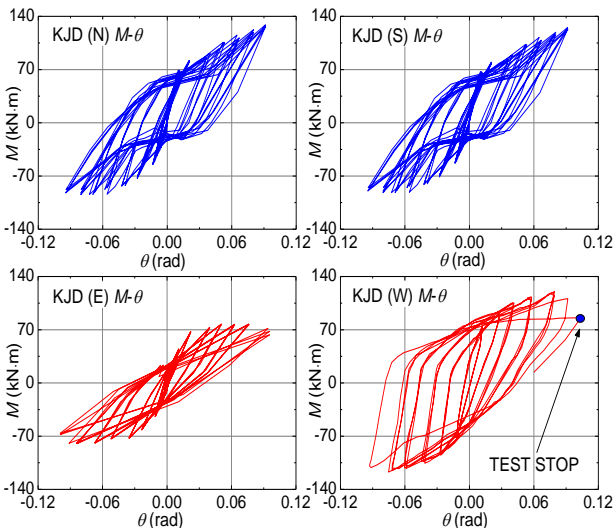

(a) Hysteresis curves of KJD spatial joint
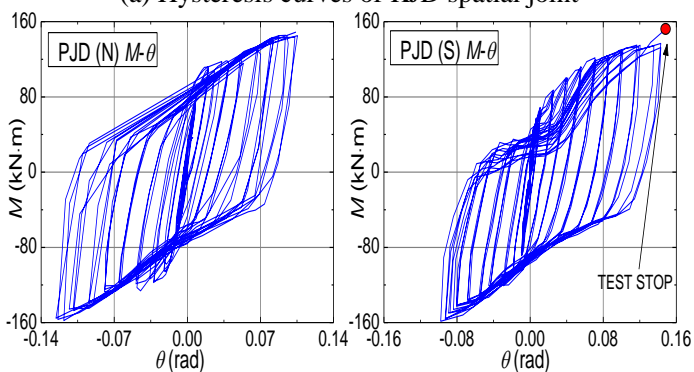

(b) Hysteresis curves of PJD planar joint

Figure 11. Hysteresis curves of the test joints
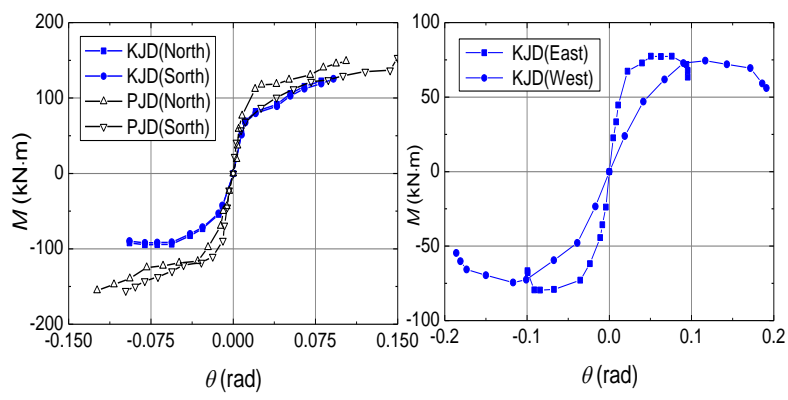

Figure 12. Skeleton curves of test specimens

The $M-\theta$ hysteresis curves for all joints in this test are shown in Figure 11. The skeleton curve for each joint specimen in each direction is illustrated in Figure 12. As observed from the figures, the hysteresis curve of each joint appeared as fusiform without pinching, thereby indicating that the joint of the T-stub connection possessed good ductility and energy dissipation characteristics. Additionally, a decline in their bearing capacity appeared, because that the column web tear in the minor axis direction caused the decline in the bearing capacity of the west side of the minor axis of the connection. The result of the analyses of the yield moment resistance and corresponding yielded rotation angle, as well as the ultimate moment resistance and corresponding ultimate rotation angle of each joint specimen in the test in each direction is shown in Table 3. The joint behavior obtained from the Finite Element analysis has an acceptable agreement with the test data demonstrate a good correlation. 
TABLE III.

TEST Results AND FEA RESUlts

\begin{tabular}{|c|c|c|c|c|c|c|c|c|c|c|}
\hline \multirow{2}{*}{ Joint No. } & \multirow{2}{*}{ Direction } & \multirow{2}{*}{ Loading Direction } & \multicolumn{2}{|c|}{ Yield state(Test ) } & \multicolumn{2}{|c|}{ Ultimate state(Test ) } & \multicolumn{2}{|c|}{ Yield state(FEA) } & \multicolumn{2}{|c|}{ Ultimate state(FEA ) } \\
\hline & & & $M_{y}(k N \cdot m)$ & $\theta_{y}(\mathrm{rad})$ & $M_{u}(k N \cdot m)$ & $\theta_{u}(\mathrm{rad})$ & $M_{y}(k N \cdot m)$ & $\theta_{y}(\mathrm{rad})$ & $M_{u}(k N \cdot m)$ & $\theta_{u}(\mathrm{rad})$ \\
\hline \multirow{4}{*}{ PJD } & \multirow{2}{*}{ North } & Positive & 76.38 & 0.008 & 148.79 & 0.104 & 81.20 & 0.009 & 152.36 & 0.112 \\
\hline & & Negative & -69.6 & -0.011 & -157.85 & -0.118 & -80.96 & -0.012 & -163.22 & -0.114 \\
\hline & \multirow{2}{*}{ South } & Positive & 68.76 & 0.011 & 153.37 & 0.15 & 73.76 & 0.014 & 153.37 & 0.151 \\
\hline & & Negative & -89.13 & -0.009 & -158.5 & -0.098 & -92.23 & -0.0012 & -163.51 & -0.146 \\
\hline \multirow{8}{*}{ KJD } & \multirow{2}{*}{ North } & Positive & 61.89 & 0.011 & 128.88 & 0.091 & 95.24 & 0.010 & 211.79 & 0.079 \\
\hline & & Negative & -49.455 & -0.013 & -92.27 & -0.095 & -106.49 & -0.017 & -204.24 & -0.080 \\
\hline & \multirow{2}{*}{ South } & Positive & 61.89 & 0.011 & 125.37 & 0.091 & 80.81 & 0.007 & 204.88 & 0.085 \\
\hline & & Negative & -49.455 & -0.013 & -92.08 & -0.08 & -94.19 & -0.008 & -212.48 & -0.074 \\
\hline & \multirow{2}{*}{ East } & Positive & 23.29 & 0.013 & 76.96 & 0.121 & 40.36 & 0.009 & 97.22 & 0.064 \\
\hline & & Negative & -24.82 & -0.013 & -79.41 & -0.145 & -37.44 & -0.009 & -90.24 & -0.056 \\
\hline & \multirow{2}{*}{ West } & Positive & 23.73 & 0.018 & 120.29 & 0.079 & 41.19 & 0.009 & 93.06 & 0.061 \\
\hline & & Negative & -22.84 & -0.017 & -117.2 & -0.075 & -38.40 & -0.009 & -101.61 & -0.058 \\
\hline
\end{tabular}

\section{Analysis of the Degradation of Rotational Stiffness}

Rotational stiffness of the joint before the yield load corresponded to the moment-rotation tangent stiffness. After entering the plastic state, the bending moment and the rotation angle showed nonlinear properties. For the purpose of convenience, secant stiffness was commonly used to represent the rotational stiffness. Hence, the rotational stiffness of the joint was calculated as follows:

$$
K_{i}=\frac{\left|+M_{i}\right|+\left|-M_{i}\right|}{\left|+\theta_{i}\right|+\left|-\theta_{i}\right|}
$$

$M_{i}$ is the peak value of the moment bearing capacity under certain level of loads, and $\theta_{i}$ is the rotation that corresponds to the peak value of the moment bearing capacity under certain levels of loads.
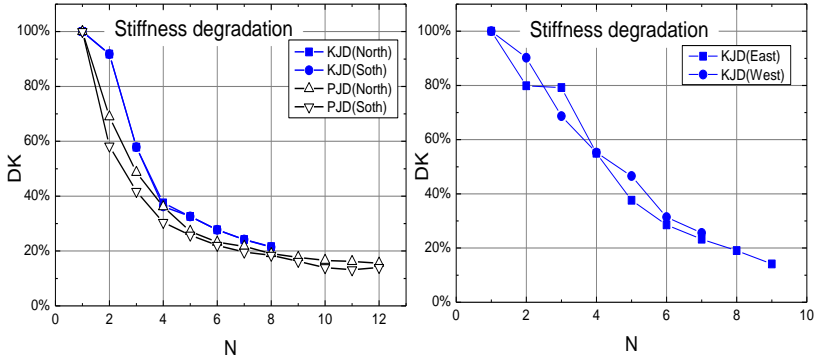

Figure 13. Rotational stiffness degradation curves

The initial rotational stiffness at the north and south sides of the planar interior joint (PJD) are $7563.73 \mathrm{kN} \cdot \mathrm{m} / \mathrm{rad}$ and $7627.53 \mathrm{kN} \cdot \mathrm{m} / \mathrm{rad}$ respectively, and the initial rotational stiffness at the south and north sides in the major axis plane of the corresponding 3D interior joint (KJD) are both $4639.58 \mathrm{kN} \cdot \mathrm{m} / \mathrm{rad}$. When the loads applied to the minor axis plane of the 3D interior joint (KJD) are taken into consideration, the initial rotational stiffness of the major axis is about 38\% lower than that of the planar exterior joint (PJD). The curve showing the rotational stiffness of the joint degenerated with the increase in the load is shown in Figure 13 , in which DK represents the stiffness degradation rate and $\mathrm{N}$ represents the load level. With respect to the semi-rigid joints, the initial rotational stiffness degradation of the plane joint was faster than that of the space joint. When the planar joints were destructed, the rotational stiffness degraded to lower than $20 \%$ of the initial value.

\section{Ductility Coefficient of the Rotation Angle}

The ratio of the ultimate rotation angle $\theta_{u}$ to the yield rotation angle $\theta_{y}$ was used to describe the ductility coefficient. The ductility coefficients of the test joints in all directions are shown in Table 4 and were expressed as the average of the major axis and minor axis. The ductile coefficient of connection is the average value in the positive and negative directions of the major and minor axis. When the loads of $3 \mathrm{D}$ joints in the minor axis plane are taken into consideration, the ductility of the 3D joints in the major axis plane decreased. According to the table5, the ductile coefficient of the 3D joint (KJD) in the major axis plane was $35.91 \%$ lower than that of the planar interior joint (PJD). From the above analysis, it can be concluded that the ductile coefficient of the 3D joints was lower than that of the planar joints.

TABLE IV

DUCTILITY FACTOR OF SPECIMENS

\begin{tabular}{|c|c|c|c|c|}
\hline \multirow{2}{*}{ Joint ID } & \multicolumn{2}{|c|}{ Major axis } & \multicolumn{2}{c|}{ Minor axis } \\
\cline { 2 - 5 } & TEST & $\boldsymbol{F E A}$ & $\boldsymbol{T E S T}$ & $\boldsymbol{F E A}$ \\
\hline PJD & 11.75 & 11.3 & - & - \\
\hline KJD & 7.53 & 7.18 & 11.15 & 10.97 \\
\hline
\end{tabular}




\section{E. Energy Dissipation Capacity}

In the case of the energy dissipation capacity of the joint, the equivalent viscous damping coefficient $h_{e}$ was typically used to evaluate the energy dissipation behavior of the structure under the action of a cyclic reciprocating load. The calculation method for this coefficient is shown in Figure 14, while calculation results are shown in Table 5. As observed from Table 5, the equivalent viscous damping coefficient of a joint is the average value in the positive and negative directions of the major and minor axes. When the loads of the 3D joint in the minor axis plane were taken into consideration, the equivalent viscous damping coefficient of the 3D joint (KJD) was relatively lower than that of the planar interior joint (PJD), On the basis of the above analyses, when the impact of loads on the joint in the minor axis plane and the locations of the joints at the frame are taken into consideration, they have varying degrees of influence on the joints' energy dissipation characteristics.

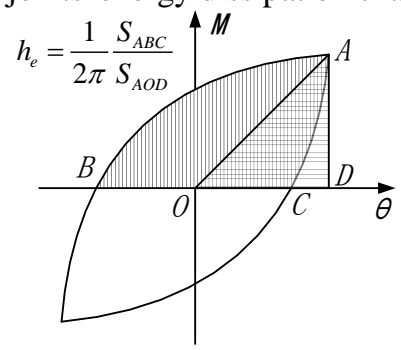

Figure 14. Equivalent viscous damping coefficient calculation diagram

TABLE V.EQUIVALENT VISCOUS DAMP COEFFICIENT

\begin{tabular}{|c|c|c|c|c|}
\hline \multirow{2}{*}{ Joint ID } & \multicolumn{2}{|c|}{ Major axis } & \multicolumn{2}{c|}{ Minor axis } \\
\cline { 2 - 5 } & $\boldsymbol{T E S T}$ & $\boldsymbol{F E A}$ & $\boldsymbol{T E S T}$ & $\boldsymbol{F E \boldsymbol { A }}$ \\
\hline PJD & 0.295 & 0.324 & - & - \\
\hline KJD & 0.284 & 0.292 & 0.229 & 0.247 \\
\hline
\end{tabular}

VI. CONCLUSIONS

The following conclusion is obtained by the research:

(1) The joints with $\mathrm{T}$ stub were typical semi rigid connection. This type of connection has a certain bending moment bearing capacity, a reasonably large initial stiffness, and better deformation capacity.

(2) For the joint with a subdivided T-stub as the connection form, the plastic hinge of the joint mainly appeared in the junction of the web and flange of the T-stub, where the plastic strain development was the fastest and most obvious.

(3) The 3D joint with $\mathrm{T}$ stub were under spatial cyclic loads in two directions so that the joint's moment bearing capacity, hysteretic characteristics, rotational stiffness, and ductile coefficients are lower than plane joint, which means that the model of the joint and the spatial effects of the loads have quite large influences on mechanical characteristic of the connection.

\section{ACKNOWLEDGMENT}

The authors are grateful for financial support from National Science Foundation of China (NSFC) (No.51278238), Researching on the seismic performance and establishment of stress model about strong-weak axis of semi-rigid beam-column connections.

\section{REFERENCES}

[1] Hao Jiping, Li Wenling. Finite element analysis for the top-and-seat angle minor axis connection of semi-rigid steel beam-column joints. China Civil Engineering Journal, 2007, 09:36-42.

[2] Wang Zhan, Wang Tao. Experiment and finite element analysis for the end plate minor axis connection of semi-rigid steel frames [J] China Civil Engineering Journal, 2012, 08:83-89.

[3] Wang Yan, FengShuang, Wang Yutian. Experimental study on hysteretic behavior for rigid-reinforced connections [J]. China Civil Engineering Journal, 2012, S1:96-101.

[4] Wang Yan, Mao Hui. Study on Seismic Performance of the End Beam Expand Flange Connection [J]. China Civil Engineering Journal, 2012, S1:96-101.

[5] Shi Wenlong, Li Guoqiang, Xiao Yong et al. Cyclic Loading Tests on Composite Beam-to-Column Joints with Semi-rigid Connections [J]. Journal of Building Structures, 2008, 05:57-66.

[6] Li Zeshen, Li Xiumei, Zheng Xiaowei. Experimental study and numerical investigation on hysteretic behavior of T-stub semi-rigid beam-to-column connections [J]. Journal of Building Structures, 2014, 07:61-68.

[7] Li Feng xia, Bu Xin, Wang Xinwu. Research on Hysteretic Behavior of the Slit T Steel Beam-Column Connections [J]. Building Science, 2010, 05:28-32.

[8] Wang Xinwu. Research on Beam-to-Column Connections of Steel Frame [D].Wuhan University of Technology. 2003.

[9] Fan Jiansheng, Zhou Hui, Nie Jianguo et al. Experimental study on seismic performance of three-dimensional composite beam-to-column joints [J]. China Civil Engineering Journal, 2014, 04:47-55.

[10] Fan Jiansheng1, Zhou Hui1, Nie Jianguo et al. Experimental study on seismic performance of three-dimensional composite beam-to-column joints [J]. Journal of Building Structures, 2011, 12:37-45.

[11] Kawaguchi J, Morino S, Sugimoto T. Elasto-plastic behavior of concrete-filled steel tubular three dimensional sub assemblages [C]. Proceedings of an Engineering Foundation Conference. Reston VA, USA:ASCE, 1992:726-741.

[12] Nishiyama I. Seismic test facility for three dimensional beam-tocolumn sub assemblages [D]. Tachihara:Building Research Institute. Department of Production Engineering, 1999.

[13] FEMA-350 Recommended seismic design criteria for new steel structural buildings [S]. 2000.

[14] FEMA-351 Recommended seismic evaluation and upgrade criteria for existing welded steel moment-frame buildings [S]. 2000.

[15] FEMA-461 Interim Testing Protocols for Determining the Seismic Performance Characteristics of Structural and Nonstructural Components[S].2007. 